\title{
UJI ABSORBSI PENCELUPAN KAIN POLIESTER MENGGUNAKAN PEWARNA DISPERSE
}

\author{
Absorption Test on Dyeing of Polyester Fabrics Using Disperse Dyes
}

\author{
Budhi Indrawijaya \\ Program Studi Teknik Kimia, FT-UNPAM, Tangerang Selatan, 15417, Indonesia \\ Email : budhi.indrawijaya@gmail.com
}

\begin{abstract}
ABSTRAK
Serat poliester pada umumnya dicelup dengan zat warna dispersi. Penyerapan zat warna dispersi pada kesetimbangan adalah baik tetapi pada difusi kedalam serat sangat lambat. Beberapa zat warna dispersi mempunyai kecepatan difusi yang cukup besar sehingga memungkinkan celupan akan muda atau sedang dalam waktu pencelupan yang tidak terlalu lama. Faktor-faktor yang mempengaruhi jumlah zat warna yang terserap dalam serat poliester adalah temperatur pencelupan dan $\mathrm{pH}$ zat warna. Oleh karena itu, penelitian ini bertujuan untuk mengetahui temperatur dan $\mathrm{pH}$ pencelupan yang memiliki absorbsi optimum. Metode pencelupan yang digunakan adalah metode HT/HP dengan variabel yaitu temperatur pencelupan, $\mathrm{pH}$ dan jenis pewarna disperse. Analisa yang digunakan untuk uji absorbsi adalah analisa spektrokolorimetri dengan menggunakan alat Computer Color Matching dan analisa spektrofotometri dengan menggunakan spektrofotometri DR6000. Berdasarkan hasil penelitian diperoleh absorbsi optimum adalah pada temperatur pencelupan tinggi dan $\mathrm{pH}$ pewarna disperse yang bersifat asam.
\end{abstract}

Kata kunci : Poliester, Pewarna Disperse, Absorbsi, Spektrofotometri

\begin{abstract}
Polyester fibers are generally dyed with disperse dyes. The absorption of disperse dyes at equilibrium is good but diffusion into the fiber is very slow. Some of disperse dyes have a considerable diffusion velocity that allowing the dye to be light or medium in a shorter dyeing time. The factors which affects the amount of dyestuff absorbed in the polyester fibers are the dyeing temperature and $\mathrm{pH}$ of the dyes. Therefore, this study aims to determine the temperature and $\mathrm{pH}$ of dyeing which has the optimum absorption. The dyeing method used is HT/HP method with variable of dyeing temperature, $\mathrm{pH}$, and disperse dye type. The analysis used for absorption test is spectrocolorimetric analysis using Computer Color Matching and spectrophotometric analysis using Spektrofotometri DR6000. Based on the result of this research, the optimum absorption is obtained at high dyeing temperature and acidic disperse dye pH.
\end{abstract}

Keywords : Polyester, Disperse Dyes, Absorption, Spectrophotometric 


\section{PENDAHULUAN}

Pencelupan adalah suatu proses pemberian warna pada bahan tekstil secara merata dan baik, sesuai dengan warna yang diinginkan. Didalam pencelupan juga ada beberapa hal yang harus diperhatikan, diantaranya adalah zat warna, serat yang dipakai dan metode pencelupan itu sendiri [1].

Pemilihan zat warna yang sesuai untuk serat merupakan suatu hal yang penting. Pewarnaan akan memberikan nilai jual yang lebih tinggi. Selain itu efektifitas kecocokan warna harus diperhatikan kerena merupakan literatur utama penentu mutu produk tekstil.

Serat poliester merupakan serat sintetis yang banyak digunakan dalam industri khususnya industri tekstil kerena sifatnya yang mudah, murah, kekuatan tinggi, ketahanan baik, ringan, titik lebur tinggi dan dapat diproduksi dalam jumlah banyak. Kelebihan dan kekurangan dari serat poliester ini akan dapat dioptimalkan dengan mencampurnya dengan serat - serat alam atau serat sintetis lainnya, sehingga menambah nilai daya guna. Serat poliester mempunyai sifat hidrofob sehingga untuk mencelupnya harus menggunakan zat warna yang tepat [2].

Serat poliester mengandung gugus ester dan memiliki keteraturan struktur rantai yang menyebabkan rantai-rantai dapat saling berdekatan, sehingga gaya antar rantai polimer poliester dapat bekerja membentuk struktur yang teratur. Poliester merupakan serat sintetik yang bersifat hidrofob karena terjadi ikatan hidrogen antara gugus - $\mathrm{OH}$ dan gugus $\mathrm{COOH}$ dalam molekul tersebut.Oleh karena itu serat polierter sulit didekati air atau zat warna.
Untuk dapat mendekatkan air terhadap serat yang hidrofob, maka kekuatan ikatan hidrogen dalam serat perlu dikurangi. Kenaikan suhu dapat memperbesar fibrasi molekul, akibatnya ikatan hidrogen dalam serat akan lemah dan air dapat mendekati serat. Disamping sifat hidrofob, faktor lain yang menyulitkan pencelupan ialah kerapatan serat poliester yang tinggi sekali sehingga sulit untuk dimasuki oleh molekul zat warna.Derajat kerapatan ini akan berkurang dengan adanya kenaikan suhu karena vibrasinya bertambah dan akibatnya ruang antar molekul makin besar pula molekul zat warna akan masuk dalam ruang antar molekul.

Zat warna dispersi adalah Zat warna yang kelarutannya dalam air sangat sedikit dan digunakan untuk mewarnai serat-serat tekstil yang bersifat hidrofob [3]. Pewarna Disperse memiliki kelarutan air sedikit karena kehadiran kutub substituen dalam struktur molekulnya. Molekul warna ini mampu menembus ke dalam serat hidrofobik buatan seperti yang ada pada selulosa asetat, nilon atau poliester. Pewarna tersebut jauh lebih larut dalam serat dibandingkan dalam air sehingga memungkinkan untuk pewarnaan yang mendalam [4]. Zat warna ini mempunyai berat molekul yang kecil dan tidak mengandung gugus pelarut. Dalam pemakaiannya diperlukan zat pembantu yang berfungsi untuk mendispersikan zat warna dan mendistribusikannya secara merata didalam larutan yang disebut zat pendispersi.

Metode pencelupan yang digunakan pada penelitian ini adalah metode HT/HP. Pencelupan dengan suhu tinggi selalu disertai dengan tekanan tinggi. Tekanan berfungsi untuk menaikkan suhu proses dan membantu 
difusi zat warna ke dalam serat. Pencelupan dilakukan pada mesin tertutup tanpa bantuan zat pengemban.

Faktor-faktor lain yang mempengaruhi jumlah zat warna yang terserap dalam serat poliester adalah temperatur pencelupan dan $\mathrm{pH}$ zat warna. Oleh karena itu penelitian ini bertujuan untuk mengetahui tingkat absorbsi serat poliester menggunakan pewarna disperse dengan temperatur pencelupan dan $\mathrm{pH}$ zat warna bervariasi.

\section{BAHAN DAN METODE}

\section{Alat dan bahan}

Alat yang digunakan adalah botol stock dyestuff, magnetic stirring rod, pot mini color, $\mathrm{pH}$ meter, mesin aupet, mesin aukitchen, mesin mini color, spektrofotometri DR6000, kuvet.

Bahan yang digunakan pada penelitian ini adalah kain Poliester 100\%, pewarna Disperse Zenix Navy PRSF dan Dianix Red Plus, sandacid PBN, sansolt RE-5.

\section{Membuat larutan dyestuff}

Klik Aupet Main Menu pada komputer kemudian pilih Making stock solution. Ketik kode dyestuff disperse 0,1\% (\%w/v) lalu klik Making. Letakkan botol pada timbangan dalam mesin Aupet lalu klik OK, kemudian botol akan secara otomatis terisi air dingin. Kemudian masukkan dyestuff disperse ke dalam botol sesuai dengan jumlah yang ditunjukkan pada layar komputer, yaitu sebanyak 0,5 gram. Apabila sudah sesuai, maka klik OK kemudian botol akan berpindah dan terisi air panas hingga volume larutan mencapai $500 \mathrm{ml}$.

Membuat resep pencelupan dyestuff + chemical
Letakkan pot-pot mini color pada meja putar dalam mesin aukitchen. Ketik data resep pada komputer aukitchen, yaitu Sandacid PBN sebanyak 1,25 ml, Sunsolt RE-5 sebanyak 1,5 $\mathrm{ml}$ serta larutan dyestuff disperse $0,1 \%$ sebanyak $5 \mathrm{ml}$, serta total volume larutan adalah $70 \mathrm{ml}$. Kemudian klik OK maka secara otomatis larutan-larutan tersebut terisi ke dalam pot mini color.

\section{Pencelupan Variasi pH}

Siapkan larutan Acetic Acid dan soda Ash, serta 5 larutan jadi dari pot mini color. Pada pot mini color 1 merupakan larutan standar dengan $\mathrm{pH}$ 5. Kemudian masukkan larutan Acetic Acid ke dalam pot mini color 2 hingga $\mathrm{pH}$ mencapai 3. Masukkan soda Ash pada pot mini color 3, 4, dan 5 hingga $\mathrm{pH}$ menjadi kurang lebih 7, 9 dan 11 secara berurutan. Kemudian pasang kain poliester $100 \%$ seberat 10 gram pada holder dan masukkan ke dalam pot mini color dan tutup rapat. Masukkan pot mini color tersebut ke dalam mesin mini color pada suhu $135^{\circ} \mathrm{C}$ selama 2 jam. Setelah proses pencelupan selesai, keringkan kain menggunakan mesin dryer dan lakukan uji absorbsi kain menggunakan Computer Color Matching (CCM) serta uji absorbsi residu larutan pencelupan menggunakan mesin spektrofotometri DR6000. Lakukan proses tersebut pada kedua pewarna Dispersi.

\section{Pencelupan Variasi Temperatur}

Siapkan 16 larutan jadi dari pot mini colordan kain poliester $100 \%$ seberat 10 gram. Kemudian pasang kain poliester $100 \%$ pada holder dan masukkan ke dalam pot mini color 
dan tutup rapat. Masukkan pot mini color tersebut ke dalam mesin mini color dan keluarkan pada saat suhu mencapai $70^{\circ} \mathrm{C}, 80^{\circ} \mathrm{C}$, $90^{\circ} \mathrm{C}, 100^{\circ} \mathrm{C}, 110^{\circ} \mathrm{C}, 120^{\circ} \mathrm{C}, 130^{\circ} \mathrm{C}, 135^{\circ} \mathrm{C}$, $135^{\circ} \mathrm{C}$ selama 25 menit, dan pada saat penurunan suhu $135^{\circ} \mathrm{C}, 120^{\circ} \mathrm{C}, 110^{\circ} \mathrm{C}, 100^{\circ} \mathrm{C}$, $90^{\circ} \mathrm{C}, 80^{\circ} \mathrm{C}$ serta $70^{\circ} \mathrm{C}$ secara berurutan. Setelah proses pencelupan selesai, keringkan kain menggunakan mesin dryer dan lakukan uji absorbsi kain menggunakan Computer Color Matching (CCM). Kemudian lakukan pencelupan ulang menggunakan larutan residu dari pencelupan sebelumnya dengan suhu $135^{\circ} \mathrm{C}$ selama $2 \mathrm{jam}$. Setelah proses pencelupan selesai, keringkan kain pencelupan larutan residu menggunakan mesin dryer dan lakukan uji absorbsi kain tersebut menggunakan Computer Color Matching (CCM). Lakukan proses tersebut pada kedua pewarna Dispersi.

\section{Analisa CCM}

CCM (Computer Color Matching) merupakan suatu sistem untuk mengukur besarnya tingkat absorbsi dan konsentrasi zat warna yang terkandung di dalam suatu objek (dalam hal ini adalah kain) dengan menggunakan metode Spektrocolorimeter yang didasarkan pada perbedaan warna terhadap warna acuan (Color Sample). Pengukuran dilakukan dengan meletakkan kain pada alat CCM kemudian data absorbsi akan mucul pada komputer CCM.

\section{Analisa Spektrofotometri}

Spektrofotometri merupakan suatu metoda analisa yang didasarkan pada pengukuran serapan sinar monokromatis oleh suatu lajur larutan berwarna pada panjang gelombang spesifik dengan menggunakan monokromator prisma atau kisi difraksi dengan detektor fototube. Pengukuran dilakukan dalam tiga tahap yaitu (1) penentuan panjang gelombang serapan maksimum dengan membaca serapan sinar/absorbansi larutan celup $0,1 \%$ pada kisaran panjang gelombang 400-700 nm dengan interval $5 \mathrm{~nm}$ menggunakan spektrofotometri DR6000 dan Tentukan panjang gelombang serapan maksimumnya, (2) Pembuatan Kurva Standar Absorbansi vs konsentrasi larutan dyestuff dengan absorbansi sebagai sumbu $\mathrm{Y}$ dan konsentrasi larutan dyestuff sebagai sumbu X, (3) Penentuan Konsentrasi Larutan Sampel dengan cara menghitung dari persamaan garis lurus yang telah diperoleh.

\section{HASIL DAN PEMBAHASAN}

\section{Uji Absorbsi Kain Poliester pada Temperatur Pencelupan Bervariasi}

Hasil uji absorbsi pada larutan celup awal dapat dilihat pada Tabel 1. Sedangkan hasil uji absorbsi varian temperatur pencelupan menggunakan residu larutan celup dapat dilihat pada Tabel 2.

\section{Pengaruh Temperatur Pencelupan Terhadap Kain Poliester}

Dalam proses pencelupan poliester menggunakan zat warna dispersi diperlukan pemanasan, dimana dalam proses pemanasan kelarutan zat warna akan bertambah besar, molekul-molekul zat warna relatif bergerak lebih cepat dan aktif sehingga zat warna lebih mudah masuk ke dalam serat.

Dengan kenaikan suhu, kecepatan difusi zat warna akan bertambah besar karena energi kinetik zat warna akan bertambah besar. Struktur molekul zat warna yang sederhana atau lebih kecil akan mempunyai energi kinetik yang lebih besar dibandingkan dengan zat warna yang mempunyai energi kinetik yang 
kecil dicampur, maka zat warna yang masuk lebih dulu kedalam serat adalah

Tabel 1. Uji Absorbsi Kain Poliester Varian Temperatur Pencelupan

\begin{tabular}{|c|c|c|}
\hline $\begin{array}{c}\text { Temperatur } \\
\text { Pencelupan }\end{array}$ & $\begin{array}{c}\text { Zenix Navy } \\
\text { PRSF }\end{array}$ & $\begin{array}{c}\text { Dianix Red } \\
\text { Plus }\end{array}$ \\
\hline $70^{\circ} \mathrm{C}$ & 0,0234 & 0,0516 \\
\hline $80^{\circ} \mathrm{C}$ & 0,0378 & 0,0648 \\
\hline $90^{\circ} \mathrm{C}$ & 0,0415 & 0,0967 \\
\hline $100^{\circ} \mathrm{C}$ & 0,0573 & 0,1432 \\
\hline $110^{\circ} \mathrm{C}$ & 0,1136 & 0,3254 \\
\hline $120^{\circ} \mathrm{C}$ & 0,1968 & 0,3868 \\
\hline $130^{\circ} \mathrm{C}$ & 0,3782 & 0,4526 \\
\hline $135^{\circ} \mathrm{C}$ & 0,4479 & 0,45 \\
\hline $135^{\circ} \mathrm{C} \mathrm{x} 20^{\prime}$ & 0,4562 & 0,4847 \\
\hline $135^{\circ} \mathrm{C} \searrow$ & 0,459 & 0,4454 \\
\hline $120^{\circ} \mathrm{C} \searrow$ & 0,4478 & 0,4681 \\
\hline $110^{\circ} \mathrm{C} \searrow$ & 0,4623 & 0,4225 \\
\hline $100^{\circ} \mathrm{C} \searrow$ & 0,4555 & 0,4382 \\
\hline $90^{\circ} \mathrm{C} \searrow$ & 0,4509 & 0,4368 \\
\hline $80^{\circ} \mathrm{C} \searrow$ & 0,4563 & 0,4322 \\
\hline $70^{\circ} \mathrm{C} \searrow$ & 0,4483 & 0,4491 \\
\hline & & \\
\hline & & \\
\hline & & \\
\hline & & \\
\hline & & \\
\hline & & \\
\hline & & \\
\hline & & \\
\hline
\end{tabular}

Tabel 2. Uji Absorbsi Kain Poliester Varian Temperatur Pencelupan Larutan Residu

\begin{tabular}{|c|c|c|}
\hline $\begin{array}{c}\text { Temperatur } \\
\text { Pencelupan }\end{array}$ & $\begin{array}{c}\text { Zenix Navy } \\
\text { PRSF }\end{array}$ & $\begin{array}{c}\text { Dianix Red } \\
\text { Plus }\end{array}$ \\
\hline $70^{\circ} \mathrm{C}$ & 0,3906 & 0,3569 \\
\hline $80^{\circ} \mathrm{C}$ & 0,3693 & 0,3494 \\
\hline
\end{tabular}

\begin{tabular}{|c|c|c|}
\hline $90^{\circ} \mathrm{C}$ & 0,3987 & 0,3075 \\
\hline $100^{\circ} \mathrm{C}$ & 0,3562 & 0,2577 \\
\hline $110^{\circ} \mathrm{C}$ & 0,2871 & 0,1611 \\
\hline $120^{\circ} \mathrm{C}$ & 0,2193 & 0,0511 \\
\hline $130^{\circ} \mathrm{C}$ & 0,0452 & 0,0098 \\
\hline $135^{\circ} \mathrm{C}$ & 0,0096 & 0,0088 \\
\hline $135^{\circ} \mathrm{C} \times 20^{\prime}$ & 0,0024 & 0,0042 \\
\hline $135^{\circ} \mathrm{C} \searrow$ & 0,0023 & 0,0037 \\
\hline $120^{\circ} \mathrm{C} \searrow$ & 0,0014 & 0,0028 \\
\hline $110^{\circ} \mathrm{C} \searrow$ & 0,002 & 0,0023 \\
\hline $100^{\circ} \mathrm{C} \searrow$ & 0,0013 & 0,0018 \\
\hline $90^{\circ} \mathrm{C} \searrow$ & 0,0014 & 0,0018 \\
\hline $80^{\circ} \mathrm{C} \searrow$ & 0,0014 & 0,0019 \\
\hline $70^{\circ} \mathrm{C} \searrow$ & 0,0017 & 0,0014 \\
\hline
\end{tabular}

yang mempunyai energi kinetik yang lebih besar, sehingga bisa menghasilkan warna yang tidak sesuai dengan yang diinginkan.

Pada penelitian ini, didapatkan bahwa semakin tinggi temperatur dan waktu pencelupan, maka absorbsi kain poliester terhadap pewarna disperse semakin besar. Hal tersebut sesuai dengan teori yang menyatakan:

a. Perpindahan atau pergerakan rantai molekul serat poliester mulai aktif pada suhu tinggi $\left(120-130^{\circ} \mathrm{C}\right)$ sehingga memberi ruang bagi molekul-molekul zat warna untuk meningkatkan penyerapan zat warna ke dalam serat.

b. Kecepatan difusi zat warna dispersi mulai meningkat pada suhu tinggi $\left(120-130^{\circ} \mathrm{C}\right)$ dan kecepatan penyerapan serta migrasi zat 
warna menjadi lebih besar sehingga akan mempercepat proses.

c. Pencelupan mulai lebih cepat karena kelarutan zat warna dispersi pada suhu tinggi $\left(120-130^{\circ} \mathrm{C}\right)$ mulai meningkat [2].

Kenaikan suhu menyebabkan lebih banyak partikel pewarna yang cepat terserap pada kain [1]. Absorbsi pencelupan kain poliester dengan pewarna dispersi Dianix Red Plus yang paling tinggi adalah saat temperatur pencelupan mencapai $135^{\circ} \mathrm{C}$ selama 20 menit sedangkan dengan pewarna dispersi Zenix Navy PRSF adalah saat temperatur mencapai penurunan temperatur $110^{\circ} \mathrm{C} \searrow$. Hal tersebut dapat dilihat pada hasil kain yang dihasilkan karena telah memenuhi standar.

\section{Uji Absorbsi Kain Poliester dengan pH Zat Warna Disperse Bervariasi}

Hasil uji absorbsi kain poliester varian ph pewarna dispersi larutan celup awal dapat dilihat pada Tabel 3. Hasil dari uji colordifference yaitu uji perbedaan warna menggunakan CCM untuk mengetahui angka perbedaan warna dari tiap sampel terhadap warna standar dapat dilihat pada Tabel 4.

Tabel 3. Uji Absorbsi Kain Poliester Varian pH Pewarna Dispersi

\begin{tabular}{|c|c|c|}
\hline $\mathbf{p H}$ & $\begin{array}{c}\text { Zenix Navy } \\
\text { PRSF }\end{array}$ & $\begin{array}{c}\text { Dianix } \\
\text { Red Plus }\end{array}$ \\
\hline 3 & 0,3167 & 0,324 \\
\hline 5 (Standard) & 0,3133 & 0,3242 \\
\hline 7 & 0,2942 & 0,3025 \\
\hline 9 & 0,2847 & 0,3102 \\
\hline 11 & 0,0854 & 0,3086 \\
\hline
\end{tabular}

Tabel 4. Data L*a*b Collor-difference

\begin{tabular}{|c|c|c|c|c|c|}
\hline Pewarna & pH & $\Delta \mathbf{E}$ & $\Delta \mathbf{L}$ & $\Delta \mathbf{a}$ & $\Delta \mathbf{b}$ \\
\hline \multirow{4}{*}{$\begin{array}{l}\text { Zenix } \\
\text { Navy } \\
\text { PRSF }\end{array}$} & 3 & $\begin{array}{c}0,587 \\
622\end{array}$ & $-0,56$ & 0,11 & 0,14 \\
\hline & 7 & $\begin{array}{c}0,592 \\
368\end{array}$ & 0,08 & 0,09 & $-0,58$ \\
\hline & 9 & $\begin{array}{c}0,176 \\
918\end{array}$ & 0 & 0,12 & 0,13 \\
\hline & 11 & $\begin{array}{c}21,75 \\
4\end{array}$ & 13,78 & $-0,66$ & 16,82 \\
\hline \multirow{4}{*}{$\begin{array}{c}\text { Dianix } \\
\text { Red Plus }\end{array}$} & 3 & $\begin{array}{c}0,940 \\
744\end{array}$ & 0,07 & 0,76 & 0,55 \\
\hline & 7 & $\begin{array}{c}2,871 \\
132\end{array}$ & 1,48 & 2,03 & 1,39 \\
\hline & 9 & $\begin{array}{c}3,253 \\
383\end{array}$ & 1,32 & 2,5 & 1,61 \\
\hline & 11 & $\begin{array}{c}2,657 \\
424\end{array}$ & 1,37 & 1,27 & $-1,89$ \\
\hline
\end{tabular}

Uji absorbsi dengan varian ph zat warna dispersi larutan celup residu dilakukan menggunakan analisa spektrofotometri dan menghasilkan konsentrasi zat pewarna residu yang dapat dilihat pada tabel 5 untuk Zenix Navy PRSF dan tabel 6 untuk Dianix Red Plus.

Tabel 5. Hasil Konsentrasi Larutan Residu Zenix Navy PRSF

\begin{tabular}{|c|c|c|}
\hline $\mathbf{p H}$ & Absorbansi & $\begin{array}{c}\text { Konsentrasi } \\
(\% \mathbf{w} / \mathbf{v})\end{array}$ \\
\hline 3 & 0,218 & 0,01014631 \\
\hline 5 & 0,813 & 0,029071247 \\
\hline 7 & 0,822 & 0,029357506 \\
\hline 9 & 0,595 & 0,022137405 \\
\hline 11 & 0,42 & 0,016571247 \\
\hline
\end{tabular}


Tabel 6. Hasil Konsentrasi Larutan Residu Dianix Red Plus

\begin{tabular}{|c|c|c|}
\hline $\mathbf{p H}$ & Absorbansi & $\begin{array}{c}\text { Konsentrasi } \\
(\% \mathbf{w} / \mathbf{v})\end{array}$ \\
\hline 3 & 0,4 & 0,015616562 \\
\hline 5 & 0,609 & 0,025022502 \\
\hline 7 & 0,558 & 0,022727273 \\
\hline 9 & 0,796 & 0,033438344 \\
\hline 11 & 0,97 & 0,041269127 \\
\hline
\end{tabular}

\section{Pengaruh pH Pewarna Dispersi Terhadap Kain Poliester}

Pada penelitian ini, penggunaan pewarna dispersi Dianix Red Plus pada semua varian $\mathrm{pH}$ menghasilkan warna yang sama apabila dilihat dengan kasat mata, dan memiliki nilai absorbsi yang hampir sama yaitu diatas 0,3. Namun pada $\mathrm{pH} 7,9$, dan 11 memiliki total perbedaan warna $(\Delta \mathrm{E})$ lebih besar dari 1 sehingga dianggap penggunaan pewarna dispersi pada $\mathrm{pH}$ tersebut tidak menghasilkan warna sesuai standar.

Penggunaan pewarna dispersi Zenix Navy PRSF pada pH 3, 7 dan 9 menghasilkan warna yang cukup sama dengan hasil kain dengan $\mathrm{pH}$ standar 5. Total perbedaan warna $(\Delta \mathrm{E})$ pada $\mathrm{pH}$ tersebut juga lebih kecil dari 1 sehingga penggunaan pewarna pada $\mathrm{pH}$ tersebut masih dapat diterima. Namun pada $\mathrm{pH}$ 11, kain yang dihasilkan memiliki warna yang sangat berbeda yaitu berwarna keabu-abuan. Total perbedaan warna $(\Delta \mathrm{E})$ pada $\mathrm{pH} 11$ juga menghasilkan nilai lebih besar dari 1 yaitu hinggga mencapai 21,76. Nilai absorbsi dari kain $\mathrm{pH}$ standar dan $\mathrm{pH} 11$ menghasilkan nilai yang jauh berbeda. Pada $\mathrm{pH}$ standar absorbsi mencapai angka 0,313 sedangkan pada pH 11 adalah 0,0854. Hal itu menunjukkan bahwa pada $\mathrm{pH} 11$ kain poliester tidak dapat mengabsorbsi pewarna dispersi secara optimal. Hal itu mugkin disebabkan oleh kondisi larutan alkali akan merusak serat polieter, dan juga akan menghidrolisa zat warna dispersi.

Hidrolisa umumnya terjadi pada zat warna dispersi jenis tertentu dimana zat warna tersebut tidak tahan pada rentang $\mathrm{pH}$ yang tidak sesuai dengan stabilitasnya. Semakin tinggi $\mathrm{pH}$ yang digunakan, maka kemungkinan zat warna terhidrolisa semakin besar. Banyak zat warna dispersi yang digunakan dapat mengalami hidrolisa pada pH 6 atau diatasnya. Adapun yang menyebabkan perbedaan hasil yang dihasilkan dari kedua pewarna dispersi tersebut dikarenakan perbedaan molekul zat warna pada keduanya. Semakin kecil molekul zat warna akan mempermudah zat warna untuk masuk kedalam serat, karena serat poliester memiliki pori-pori yang sangat kecil sehingga zat warna dispersi yang memiliki molekul kecil akan dengan sangat mudah larut dan mewarnai serat poliester.

\section{KESIMPULAN}

Berdasarkan hasil penelitian diperoleh data bahwa semakin tinggi konsentrasi kitosan yang diaplikasikan pada produk tahu maka semakin tinggi tingkat ketahanan dan umur simpan produk tahu. Adapun sampel dengan umur simpan paling baik yaitu produk tahu dengan konsentrasi kitosan sebesar 5\% yang disimpan pada suhu $4^{\circ} \mathrm{C}$. Berdasarkan uji organoleptik secara keseluruhan baik uji hedonik maupun uji deskriptif diperoleh data bahwa panelis lebih menyukai produk tahu yang dibuat dengan metode edible coating yang disimpan selama 1 hari. Pengaplikasian kitosan dengan metode koagulan menghasilkan 
produk tahu yang dapat bertahan dengan kondisi baik selama 14 hari, sedangkan produk tahu yang menggunakan metode edible coating menghasilkan produk tahu yang mampu bertahan selama 13 hari.

\section{DAFTAR PUSTAKA}

[1] Sunarto. 2008. Teknologi Pencelupan dan Pencapan Jilid 2. Direktorat Pembinaan Sekolah Menengah Kejuruan. Jakarta.

[2] Delima Suardiningsih. 2013. Perbedaan Kain Katun dengan Poliester pada Busana Kuliah Ditinjau dari Aspek Kenyamanan. Universitas Negeri Semarang. Semarang.

3] Soeprijono, P., et al. 1973. Serat-serat ekstil. Institut Teknologi Tekstil. Bandung. [4]Broadbent, Arthur D. 2001. Basic rinciples of Textile Coloration. Society of Dyers and Colourists. England.

[5] Bhatti, I.A, Adeel Shahid, et al. 2012. Dyeing of $U V$ irradiated cotton and polyester fabrics with multifunctional reactive and disperse dyes. Journal of Saudi Chemical Society. Vol.20:178-184.

[6] Cairns, D. 2009. Intisari Kimia Farmasi. Buku Kedokteran EGC. Jakarta.

[7] Deo, H.T, Desai, B.K. 1999. Dyeing of cotton and jute with tea as natural dye. Journal and Society of Dyers and Colorists. Vol.115:222-224.

[8] Harini, Bernadeta Wuri, Rini Dwiastuti, dan Lucia Wiwid Wijayanti. 2012. Aplikasi Metode Spektrofotometri Visibel untuk Mengukur Kadar Curcuminoid pada Rimpang Kunyit (Curcuma Domestica). Aplikasi Sains dan Teknologi. Yogyakarta.

[9] Hendayana, Semar, Asep Kadarohman, AA Sumarna, dan Asep Supriatna. 1994.
Kimia Analitik Instrumen. IKIP Semarang Press. Semarang.

[10] Khopkar, S. M. 1990. Konsep Dasar Kimia Analitik. Universitas Indonesia. Jakarta.

[11] Noerati, Gunawan, Muhammad Ichwan, Atin Sumihartati. 2013. Bahan Ajar Pendidikan dan Latihan Profesi Guru (PLPG) Teknologi Tekstil. Sekolah Tinggi Teknologi Tekstil. Bandung.

[12]Rasyid Djufri. 1976. Teknologi Pengelantangan, Pencelupan dan Pencapan. Institut Teknologi Tekstil. Bandung.

[13] Rodia Syamwil dan Adhi Kusumastuti. 2009. Pengetahuan Tekstil Untuk Tata Busana. TJP UNNES. Semarang.

[14] Rohman. 2007. Kimia Farmasi Analisis. Pustaka Pelajar. Yogyakarta.

[15] T. Ihara, M. Miyoshi, Y. Iriyama. 2003. Visible-light-active Titanium Oxide Photocatalyst Realized by an Oxygendeficient Structure and by Nitrogen Doping. Applied Catalysis. B: Environmental. Vol.42:403-409.

[16] Tim Fakultas Teknik. 2001. Mengindentifikasi Serat Tekstil. Direktorat Pembinaan Sekolah Menengah Kejuruan. Jakarta. 